\title{
The phenotype and genotype of adult obstructive sleep apnoea/hypopnoea syndrome
}

\author{
R.L. Riha*, T. Gislasson" and K. Diefenbach
}

ABSTRACT: Obstructive sleep apnoea/hypopnoea syndrome (OSAHS) is a common condition affecting $\sim 2-4 \%$ of the middle-aged population. A hereditary component to the condition has long been recognised but its genetic basis has been difficult to elucidate. Progress in determining the genotype of OSAHS is hampered by the lack of a consistent definition of phenotype and the large environmental influences on its expression. "Intermediate phenotypes", such as craniofacial structure, obesity and upper airway control, have been utilised. Multiple gene polymorphisms have been explored in association with the latter, as well as with the sequelae of OSAHS, such as hypertension and increased insulin resistance. To date, two genome-wide scans have identified potential regions that may be of interest in further defining the intermediate phenotypes. The present paper focuses on human studies with an update of the most recent work in the area, including a short discussion on methods of genetic studies.

\section{KEYWORDS: Gene polymorphisms, genetics, genotype, phenotype, sleep apnoea}

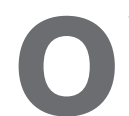
bstructive sleep apnoea/hypopnoea syndrome (OSAHS) affects up to $4 \%$ of the adult population [1]. Its pathogenesis involves the obstruction of the upper airway during sleep, resulting in repetitive breathing pauses accompanied by oxygen desaturation and arousal from sleep. The syndrome is further defined by the presence of diurnal sleepiness and cognitive impairment. OSAHS occurs throughout the entire lifespan, from neonates to the elderly [2].

In adults, sleep-disordered breathing (SDB; a repetitive upper airway obstruction during sleep alone), is prevalent within the population. SDB increases with age and is poorly associated with daytime sleepiness or other symptoms of OSAHS. Up to $20 \%$ of the population is thought to have SDB at any one time [3-5].

The sequelae of OSAHS include increased risk of driving accidents, cognitive impairment, and cerebrovascular and cardiovascular morbidity and mortality. OSAHS is an independent risk factor for diurnal hypertension [6, 7] and epidemiologically has been implicated as a risk factor for stroke (odds ratio (OR) 1.6), and "all cause" cardiovascular events (OR 2.87-3.17) [8,9]. Thus, it represents a significant public health concern. The Wisconsin Sleep Cohort Study, by prospectively investigating the association between OSAHS and the development of hypertension, found that SDB was accompanied by a substantially increased risk of developing hypertension [10]. Subjects with an apnoea/hypopnoea index (AHI) of $>15$ events $\cdot h^{-1}$ had a three-fold increased risk of developing new hypertension over a 4-yr period. Many mechanisms may mediate this vasculopathy, including repetitive hypoxaemia and hypercapnia, changes in intrathoracic pressure that lead to increases in blood pressure and elevated levels of circulating catecholamines. Evidence is also mounting that OSAHS contributes to the expression of metabolic syndrome, increased insulin resistance and a higher inflammatory state. The aetiopathogenesis

Previous article in this series: No. 1: MacLeod AK, Liewald DCM, McGilchrist MM, Morris AD, Kerr SM, Porteous DJ. Some principles and practices of genetic biobanking studies. Eur Respir J 2009; 33: 419-425.

\section{AFFILIATIONS}

*Dept of Sleep Medicine, Royal Infirmary Edinburgh, Edinburgh, UK. \#Dept of Allergy, Respiratory Medicine and Sleep, Landspitali University Hospital, Rejkjavik, Iceland.

"Institute of Clinical Pharmacology, Charité - Universitatsmedizin Berlin Berlin, Germany.

\section{CORRESPONDENCE}

R.L. Riha

Dept of Sleep Medicine

Royal Infirmary Edinburgh

51 Little France Crescent

Edinburgh

EH16 4SA

UK

Fax: 441312421776

E-mail: rlriha@hotmail.com

Received:

October 062008

Accepted after revision:

November 172008

STATEMENT OF INTEREST

None declared. 
of these sequelae of OSAHS will be discussed in subsequent articles in the series.

\section{THE PHENOTYPIC COMPLEXITY OF OSAHS Heterogeneity of OSAHS}

The key pathophysiological feature in OSAHS is the occurrence of upper airway obstruction during sleep which does not occur during wakefulness. However, the pathophysiology of OSAHS cannot be seen in isolation as a dysfunction of upper airway muscles alone, but as the consequence of a number of interrelated pathologies and risk factors. The strongest risk factors for OSAHS are obesity and ageing [11, 12]. Morbid obesity, defined as body mass index $(\mathrm{BMI})>30 \mathrm{~kg} \cdot \mathrm{m}^{-2}$, is present in $60-90 \%$ of patients with OSAHS. Central obesity, characterised by a high waist/hip ratio or increased neck circumference, is probably better correlated with OSAHS. However, not all obese subjects snore or have SDB [13].

OSAHS is more common in males and the risk of OSAHS is higher in females who are obese and post-menopausal [14]. OSAHS is also associated with craniofacial abnormalities, with jaw abnormalities being more important in thinner OSAHS patients [15]. OSAHS has a hereditary component and is much more prevalent in those with family members who have SDB or the syndrome itself [16].

Additionally, race and certain congenital conditions, such as Marfan's syndrome, Down's syndrome and the Pierre Robin sequence, predispose to the development of OSAHS, as do acquired conditions, such as acromegaly, hypothyroidism and menopause.

Alcohol ingestion exacerbates OSAHS by reducing the activity of the genioglossus muscle, thereby leading to upper airway collapse [17]. Exacerbation of the condition can also occur as a result of sedative use, sleep deprivation, tobacco use and sleeping in the supine posture [18]. Reduced nasal patency, due to congestion or anatomical defects, as well as respiratory allergies, can also significantly contribute to OSAHS [19]. Overall, it has been suggested that hereditary factors invoke $40 \%$ of the variance in the occurrence of OSAHS in the population, with the rest attributable to environmental factors [20].

Distinction must be made between adult and paediatric OSAHS. Paediatric SDB may affect up to $3 \%$ of school-aged children, with consequences very similar to those for adults [21-24]. The most common cause of OSAHS in children is related to enlargement of the tonsillar and adenoidal tissue, with surgical removal usually resulting in significant improvement. The role of obesity is somewhat controversial in childhood OSAHS [25]. Additionally, congenital craniofacial abnormalities, a well as abnormalities of brainstem control of breathing, such as the PHOXB mutations, will result in problems with breathing during sleep [26]. The present article will focus on adult OSAHS.

\section{Natural history and progression of OSAHS}

Long-term cohort studies looking at the development and progression of untreated OSAHS have not been performed. Currently, the dominant paradigm suggests that the snoring individual will progress to developing increased resistance of the upper airways culminating in SDB and, finally, OSAHS. However, there is no evidence to support this, apart from a few small studies that have demonstrated a worsening of SDB over variable periods of time $[27,28]$. There have also been a small number of studies of the cardiovascular consequences of untreated OSAHS, which have shown increased mortality from cardiovascular and cerebrovascular disease in those with more severe SDB [9]. However, these studies are not controlled for possible confounding factors, such as noncompliance with other treatment and baseline cardiovascular disease severity; no repeat studies of the patients were performed to show whether the degree of oxygen desaturation and SDB had worsened over time. Likewise, no studies have followed up paediatric patients into adulthood to see whether SDB improves, worsens or recurs after treatment. There is currently no evidence to suggest that the majority of adult snorers snored in childhood or adolescence. Lastly, the development and characteristics of OSAHS in adults also vary as a function of normal ageing [29]. The aetiology of the disease probably changes due to changes in parapharyngeal fat pad deposition [30], serotonergic dysregulation of brainstem respiratory control (due to "wear and tear") [31] and age-related changes in bony structures, such as edentulism [32]. Variations in neuromuscular control of the upper airway become more important in the elderly [33], and increased background prevalences of cardiac and cerebrovascular disease increase the likelihood of periodic breathing. The clinical phenotype of OSAHS also changes. Older subjects report less daytime sleepiness for a given level of OSAHS [34]. Furthermore, hypotheses have been postulated suggesting that the development of SDB with intermittent hypoxia may lead to ischaemic preconditioning, which may act as a protective mechanism in older subject [35]. Thus, SDB and OSAHS in the elderly are unlikely to be equivalent to the same disorders that develop in middle or young age.

\section{CLINICO-PHYSIOLOGICAL PHENOTYPES OF OSAHS}

Phenotype is the total physical appearance and constitution of a living entity [36]. The genotype and environment create the phenotype. Genotype, environment and random variation can also contribute to phenotypic expression. Therefore, a phenotype is any detectable characteristic of an organism determined by an interaction between its genotype and environment. Phenotypic plasticity, the ability of an organism with a given genotype to change its phenotype in response to changes in the environment, may be applicable to OSAHS. Thus, a particular genotype may express itself as a different phenotype at different times and in response to different environmental circumstances [37].

As discussed earlier, OSAHS can occur in a variety of conditions. In order to be able to phenotype OSAHS, a possible future classification might take the following into account: 1) physiological basis; 2) structural basis; and 3) evaluation of daytime sleepiness.

In 1999, the American Academy of Sleep Medicine Task Force developed the most widely accepted definition of OSAHS in present use [38]. OSAHS severity is based on the severity of daytime sleepiness and overnight monitoring of breathing, and both are rated separately. Although this is a very practical definition, it is not particularly useful when it comes to phenotyping OSAHS, as there is no accounting for age or sexrelated changes; in addition, intermittent phenotypes are not 
taken into account. There are few normative data in the population for the spectrum of sleep disordered breathing without symptomatology and the results obtained in phenotyping, which include the number of obstructive events during the night, are highly dependent on the technology used to measure them. It has thus been postulated that OSAHS should be broken down into intermediate phenotypes that could then be assessed in terms of their relative contribution to the overall phenotype. These include the craniofacial morphology, obesity and susceptibility to sleepiness, as well as ventilatory and upper airway control. However, we are still lacking in models that would be able to pool these factors and then assess the relative importance of the component parts in producing the whole. Difficulty arises in distinguishing those variables within the OSAHS phenotype that are central to the disease process and those that are epiphenomena. As seen in observational and epidemiological studies, various components will have greater importance in some individuals with OSAHS compared with others. The component phenotypes are discussed in the following sections.

\section{Craniofacial morphology}

This is probably one of the most important heritable determinants of OSAHS. Morphological features associated with SDB include cranial base dimensions being more obtuse, inferior displacement of the hyoid bone, macroglossia, adenotonsillar hypertrophy, increase in lower facial height, a retroposed maxilla and a short mandible [32]. The craniofacial complex comprises a number of components interdependent in growth patterns and closely linked, with the growth and shape of one component influencing others. The process is complex throughout embryogenesis and further growth from childhood to adulthood [39]. Growth of the craniofacial skeleton continues throughout adulthood and there is also significant sexual dimorphism. For instance, women have increased growth of the craniofacial skeleton with pregnancy and other hormonal changes; mandibular orientation and occlusal relationships also change throughout the life cycle [39]. Environmental mechanisms play a strong role in determining cranioskeletal growth. These include bad habits such as thumb-sucking and abnormal tongue posturing, nasopharyngeal disease, disturbed respiratory function (e.g. mouth breathing), tumours, loss of teeth, malnutrition and endocrinopathy [40]. Thus, environmental influences can significantly alter the skeleton, thereby altering phenotypic expression. Post-natal growth, head shape and facial profile also possess certain characteristics that can affect breathing. On reviewing the current knowledge in this area, mandibular position and size were found to play the greatest role in determining facial alignment and predisposition to SDB. However, the number of studies looking at this particular intermediate phenotype is very limited [41, 42]. Genes involved in the embryogenesis, growth, development and expression of the craniofacial complex are subject to very complex gene-gene and gene-environmental effects and their pathways are yet to be fully elucidated [43].

\section{Obesity}

Obesity is the most commonly identified risk factor for OSAHS. Fat deposition results in a reduction in nasopharyngeal calibre and if significant, can lead to hypoventilation due to reduced chest wall compliance [44]. There is increasing evidence that adipokines, such as leptin, may affect regulation of the respiratory centre [45]. The heritability in BMI in large sample sizes is thought to be between $25 \%$ and $40 \%$; therefore, a strong environmental influence is present [46]. Susceptibility to obesity is largely genetic but a favourable environment must exist for its phenotypic expression. Regulation of appetite and energy expenditure is complex and redundant pathways are biased towards weight gain. Information on obesity susceptibility genes is updated regularly through the human obesity gene map [47]; to date, $>300$ markers, genes and chromosomal regions have been associated or linked with human obesity phenotypes. Only a few single mutations directly linked to obesity have been found in rare cases; there are no other genetic associations resulting from a mutation affecting function or amount of gene product. The support of cellular work is also lacking at the present time.

\section{Sleepiness}

Sleepiness, as a consequence of SDB, is required to define OSAHS but does not necessarily correlate with it. There are many instances of individuals who may have an AHI of 100 but deny sleepiness or impairment during the day. There appears to be a differential susceptibility to somnolence among individuals. Sleep is regulated by neuronal and humoral mechanisms that are interdependent [48]. Interleukin (IL)-1 and tumour necrosis factor- $\alpha$ appear central to the sleep activation pathways, and other sleep-inducing cytokines include IL-10, IL-6, interferon, IL-2, IL-4, granulocyte-macrophage colony-stimulating factor, colony-stimulating factor and fibroblast growth factor [49]. Many of these cytokines are pleiotropic and also implicated in initiating or propagating the sequelae of OSAHS, particularly inflammation [50].

\section{Upper airway control}

During sleep, an increase in upper airway activity leads to snoring and upper airway obstruction, in turn leading to arousal. Arousal activates the pharyngeal muscles and restores airways patency, leading to more effective breathing. During sleep, withdrawal of tonic excitation of the hypoglossal motor neurones results in reduced firing of serotonergic medullary raphe neurones and reduced firing of noradrenergic locus coeruleus neurones. Molecular dissection techniques in recent times have shown the 5-hydroxytryptamine (5HT)2A receptor to be the predominant receptor subtype in hypoglossal motor neurones [51]. Selective serotonin reuptake inhibitors (SSRIs) have been trialled as a pharmacological therapy for increasing upper airway tone but this has led to mixed results. Incomplete responses have occurred despite increased genioglossal activity using electromyography in the awake state [52]. Until upper airway pathophysiology is more completely defined, this intermediate phenotype may continue to be elusive in terms of genetic studies.

\section{Ventilatory control}

Genetic influences have been postulated to influence the magnitude of the ventilatory response to hypoxia and hypercapnia. There is a high degree of heritability of peripheral chemoreceptor responses to hypoxia and hyperoxia in monozygotic twins [53]. Healthy family members also share reduced ventilatory responses to hypoxia. There have been a large number of studies in patients with OSAHS and their 
family members in terms of hypercapnic and hypoxia ventilatory responses, but the numbers have been very small and the results have been conflicting (table 1). It is debatable whether respiratory control problems are implicated in the pathogenesis of OSAHS. Although several studies have shown abnormalities of respiratory control, these have been shown to reverse with the use of continuous positive airway pressure; therefore, the changes may be secondary and may not necessarily be a primary manifestation of the genotype in terms of determining OSAHS.

\section{Sequelae of OSAHS}

Repetitive upper airway obstruction with attendant hypoxaemia and increased arousals has been shown to contribute to the disruption of cardiovascular, metabolic and endocrine function (these consequences will be discussed in greater detail in future papers in the series). OSAHS is an independent risk factor for diurnal hypertension and has been implicated as a risk factor for first stroke, recurrent stroke and post-stroke mortality [62]. Repetitive hypoxaemia due to SDB may play an important role in systemic inflammation and may enhance the development of atherosclerosis [63]. There is growing evidence that cell and molecular mechanisms involving inflammatory mediators are upregulated in patients with OSAHS [64]. A genetic propensity towards increased pro-inflammatory cytokine production may also exacerbate these effects [65].

OSAHS may also contribute towards the development of metabolic syndrome. Hypercytokinaemia, hyperleptinaemia, insulin resistance, hypertension and visceral obesity occur at disproportionately high levels in the population with OSAHS [66]. When obesity is controlled for, OSAHS has still been shown to be highly significantly associated with hypercytokinaemia, high leptin levels, insulin resistance and hypertension [67]. It has been somewhat easier to look at possible genetic underpinnings to the development of sequelae in OSAHS and this may potentially be useful in the future in order to monitor variability of OSAHS and predict response to treatment.

\section{ANIMAL MODELS OF OSAHS}

Whether animal models accurately reflect human disease processes is debatable; they certainly cannot replicate the phenotypic complexity of human disease. Identifying one or two key abnormalities involved in a disease process and then replicating them in an animal model under controlled conditions appears to be the ideal approach, especially when it comes to exploring biological mechanisms and testing new compounds in a definitive manner [68]. In OSAHS, animal models are difficult to develop. Various canine species are known to develop SDB and the English bulldog has been used in a number of studies on upper airway control. Inbred mice and rats have been used to explore the pathways in ventilation and upper airway control, and leptin resistance and the effects of obesity have been explored in the obese Zucker rat [69]. However, there can be marked interspecies variability in response to various chemokines and hormones. For example, opposing effects are demonstrated in the case of serotonin receptor antagonism using ritanserin (5HT2A, $2 \mathrm{C}$ and 7 receptor antagonist) between dogs and rats. One study using the normally respiring adult rat has shown that use of ritanserin results in increased phrenic and hypoglossal activity [70], while administration of the same drug in the English bulldog model of OSAHS causes decreased activity of upper airway dilator muscles with concurrent oxyhaemoglobin desaturation and collapse of the upper airway [71]. There is a tendency to assume that by discovering something in an animal model of OSAHS that something of relevance has been discovered about human OSAHS and this should be guarded against.

\section{CURRENT GENETIC APPROACHES AND THEIR LIMITATIONS}

Two general approaches in study design have been used to explore the genetic components of human disease: linkage studies and association studies.

Linkage studies have been utilised mainly in the study of single-gene disorders; they detect genetic markers throughout the genome, which are not necessarily functionally significant

TABLE 1 Studies of ventilatory control in subjects with sleep-disordered breathing (SDB), families and controls

\begin{tabular}{|c|c|c|c|c|c|c|}
\hline Reference & \multicolumn{3}{|c|}{ Subjects $\mathbf{n}$} & HVR & HCVR & HCVR and loading \\
\hline [55] & 8 & & 8 & Decreased $V^{\prime} E$ in SDB & & \\
\hline [56] & $13^{\#}$ & 32 & & No difference between relatives & No difference between relatives & \\
\hline [57] & 35 & & 17 & No difference between groups & Lower response in SDB & \\
\hline [58] & 16 & & 12 & Greater increase $V^{\prime} E$ in SDB & No difference between groups & \\
\hline [59] & $20^{\circ}$ & & 19 & No difference between groups & No difference between groups & \\
\hline$[60]$ & 37 & & 14 & No difference between groups & No difference between groups & \\
\hline [61] & 151 & & & Total subjects 485 : ventilatory va & $\begin{array}{l}\text { ability index calculated. Multiple lir } \\
\text { AHI of increased ventilatory varia }\end{array}$ & $\begin{array}{l}\text { regression showed association with } \\
\text { y. }\end{array}$ \\
\hline
\end{tabular}

Patients with SDB are normocapnic unless otherwise indicated. F: family members; HVR: hypoxic ventilatory response; HCVR: hypercapnic ventilatory response; V'E: minute ventilation; AHI: apnoea/hypopnoea index. ${ }^{\#}$ : hypercapnic patients; $"$ : children with mean \pm SD age $8 \pm 3$ yrs. 
in terms of phenotypic effect and they use extended families. Genome-wide linkage studies utilise complex statistical techniques with strength of association of a genetic locus with a phenotypic marker reported as a logarithm of the odds (LOD) score. In linkage analyses, a LOD score $>3$ is considered to indicate significant linkage (the phenotypic locus and putative genetic marker have a chance of $<1 / 1,000$ of not being linked). A score between 2 and 3 is considered to be "suggestive" of linkage and a score $<2$ is not suggestive of linkage [72]. Genetic linkage and positional cloning methods have not been so successful in identifying genes implicated in polygenic disorders. One strategic approach that may enhance the success rate includes initial detection of linkage to a quantitative trait locus, refining the chromosome localisation or fine mapping and then positionally cloning the gene concerned, and detecting the genetic polymorphisms contributing to the trait phenotype [73].

Association studies are used to identify genes involved in polygenic disorders; they determine genotype for polymorphism in candidate genes of biological relevance to the disease being investigated and use cases and appropriately matched controls (usually unrelated). The association of a genotype or phenotype with disease is a statistical finding not necessarily reflecting genetic association [73]. Association studies may currently be more useful in OSAHS, but only if they are adequately designed and powered. Candidate gene studies may be refined by using the common patterns of DNA sequence variation available (HapMap Project) [74], making the indirect association approach readily applicable and more cost-effective. In this approach, "tag" single-nucleotide polymorphisms (SNPs) are used to identify unique haplotypes. The Human Genome Project has made a SNP map possible, which is a high-density map of 200,000-600,000 SNPs and a database that contains 1.8 million SNPs [74]. Advances in SNP mapping and high-throughput SNP genotyping platforms are making it increasingly feasible to consider genome-wide association studies. The case-control method of study design has the advantage of both the increased statistical efficiency of association analysis of a complex disease and the biological understanding of the phenotype, tissues, genes, and proteins that are likely to be involved [73]. However, numerous issues relevant to the design of case-control studies must be addressed, including: choice of candidate gene and SNP; recruitment methods; control matching; and number of study subjects (especially with respect to power) [73]. Gene expression studies can also be used to identify associations between genes and OSAHS. Analysis of mRNA levels expressed by probands' genes in comparison to levels expressed by normal controls can identify genetic factors underlying the disease and the secondary molecular factors that are its consequence. Such an approach may also lead to the recognition of previously unknown pathophysiological pathways. Inherent difficulties lie in deciding which tissue to sample for mRNA or protein expression and the interpretation of findings. Replication and careful follow-up in all studies is essential, especially in the context of a disorder such as OSAHS, in which heterogeneity of phenotypic expression (including epigenetic phenomena, such as parental imprinting, disease fluctuation and sex effects, complexity of mode of inheritance, and misclassification of phenotype) can lead to dubious linkages [75]. Independent replication in subsequent cohorts in the same population or in independent populations is necessary for complete confidence in a finding. Statistical considerations in this context are also extremely important. Consistent replication in different populations is strong evidence of causality, but lack of replication does not necessarily imply lack of causality. A large number of SNPs studied may have real but modest effects on common disease risk, but the studies are underpowered, leading to false-negative reports [76]. A detailed discussion of the genomic and proteomic aspects of sleep disordered breathing has been provided by POLOTSKY and O'DONNELL [77].

\section{GENETIC ASPECTS OF THE AETIOLOGY AND SEQUELAE OF OSAHS}

To date, two genome-wide scans have been performed in SDB. PALMER et al. [78] performed a 9cM genome scan for OSAHS and obesity in 66 European-American pedigrees comprising 349 subjects. OSAHS was phenotyped on the basis of AHI alone using overnight, in-home measurement of breathing using a portable monitor (Edentec Model 3711 Digital Recorder; Nellcor, Eden Prairie, MN, USA). DNA was pooled and multipoint variance component linkage analysis was performed for the OSAHS-associated quantitative phenotypes of AHI and BMI. The analysis identified candidate regions on chromosomes 1p (LOD score 1.39), 2p (LOD 1.64), 12p (LOD 1.43) and 19p (LOD 1.40) for linkage with AHI. BMI was linked to the following regions: chromosome $2 \mathrm{p}$ (LOD 3.08), $7 \mathrm{p}$ (LOD 2.53) and $12 \mathrm{p}$ (LOD 3.41). Further statistical modelling indicated that evidence for linkage to AHI was removed after adjustment for BMI, except for regions on chromosomes $2 p$ (adjusted LOD score 1.33) and 19p (adjusted LOD 1.45). When BMI linkages were adjusted for AHI, the LOD scores were roughly halved.

A further 9cM whole genome scan was conducted in 59 African-American pedigrees in identical fashion as above. Analysis identified linkage on chromosome 8q (LOD 1.29) [79]. BMI was linked to chromosomes 4q (LOD 2.63) and 8q (LOD 2.56). Adjustment for AHI greatly reduced linkages to BMI, and vice versa.

LOD scores $<2$ are not suggestive of linkage under most circumstances, especially in the context of modest power of the sample size, lack of a reported significance threshold for the sample and the use of quantitative traits. The results of these studies must be interpreted with great caution.

In contrast, a large number of candidate gene studies have been performed in OSAHS using various definitions of the syndrome and with variable populations. To date, there has been no consistent replication of the findings of any of the studies and most are not immune to the criticism of being underpowered, poorly controlled and very poorly phenotyped. They are summarised in table 2 .

\section{IS THERE A WAY FORWARD?}

Despite sporadic reference to OSAHS in ancient times, OSAHS was first fully described and recognised in the 20th century, with effective treatment developed and refined in the last 30 yrs. However, the definitions of the disease remain rooted in the 19th century, with failure to recognise both its phenotypic complexity and the pathophysiological links 


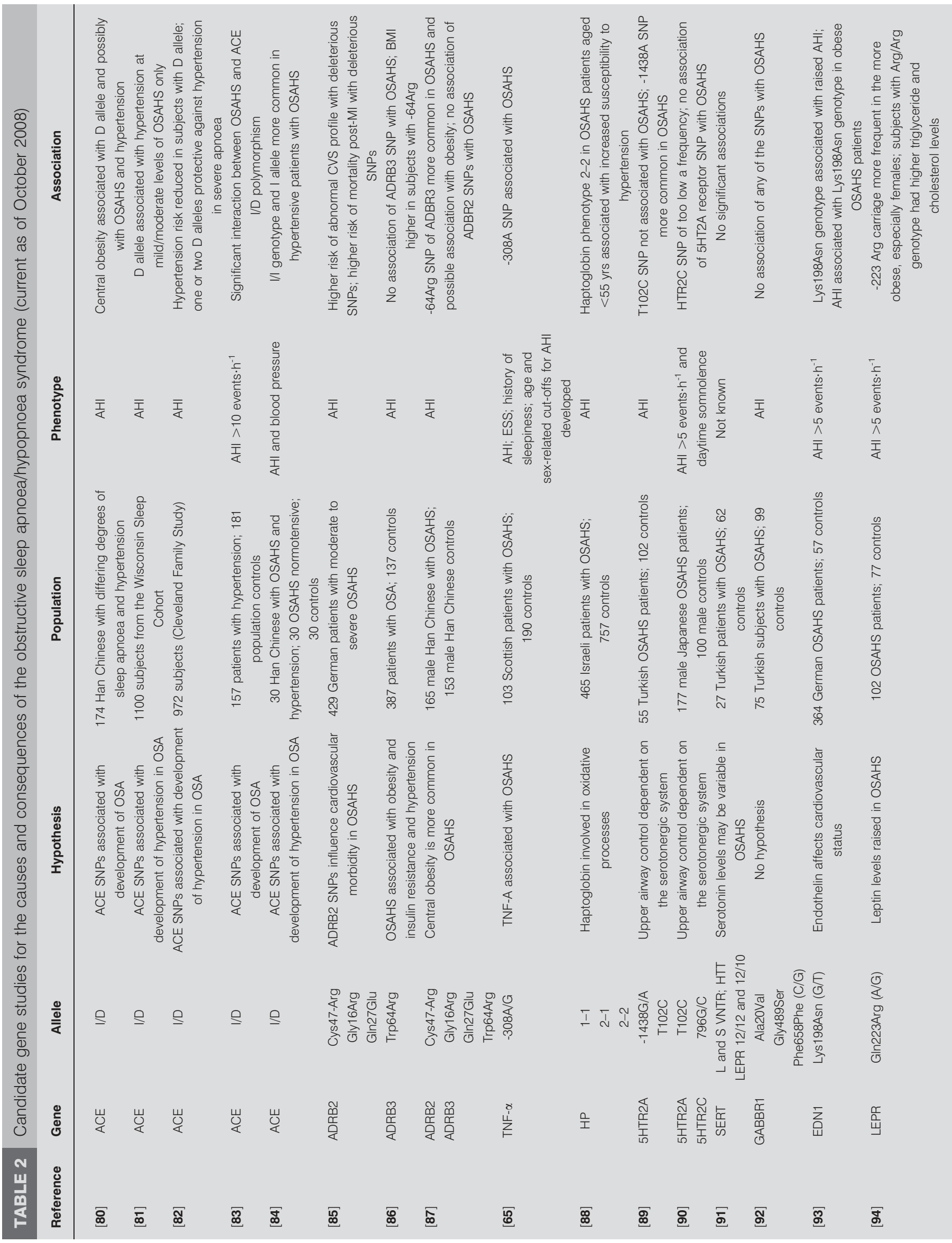




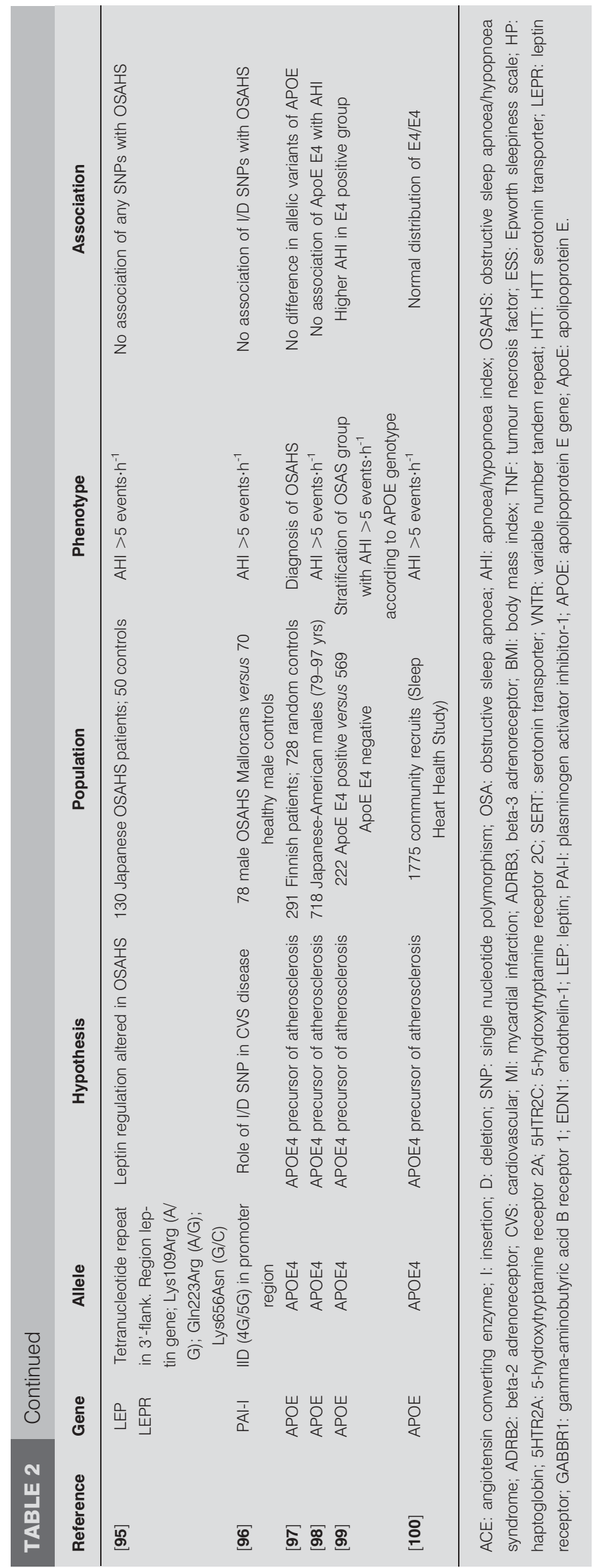

between physiological and cellular abnormalities common to it and other diseases. At present, OSAHS defies an unequivocal phenotypical definition, imbuing any approaches to conducting and interpreting epidemiological and genetic studies with nihilism. If there is to be any progress, however, it is essential to fully address the complexity of the disease using a standardised approach. This has major implications for assessing prevalence, true effects on cardiovascular and metabolic status and the long-term effectiveness of treatment in the different populations who suffer from this condition. One way of achieving this would be to correlate all variables from all the different dimensions of the disease process, using methods such as cluster analysis [101] and systems genetics [102]. Based on increased understanding of the true nature of OSAHS, a new model of the condition should be considered. Various mathematical systems could be utilised to undertake these analyses based on nonlinear modelling and chaos theory. The paradigm that OSAHS and SDB lie inextricably linked on the same disease spectrum has remained unchallenged for $>30$ yrs: there is no evidence that snoring will develop into SDB and then develop into OSAHS.

Further investigation should be undertaken into whether the OSAHS phenotype remains static throughout life, or whether it changes with time and under different environmental conditions. At present, we are limited to studying the phenotype at a single point in time, generally when it calls itself to clinical attention. Longitudinal studies, first identifying those who have OSAHS in childhood and following them through and, secondly, continuing to follow those identified with SDB in adult life, could be useful in clarifying this issue. There may be large differences in underlying genotype, for instance, between those progressing into old age with asymptomatic SDB, and those who develop symptoms and require treatment. It may be discovered that we are dealing with a range of diseases that manifest as a single phenotype at a particular point in time in the individual's life rather than a single disorder (genotype). Further study is needed in order to determine the best variables to be used to define phenotype, including age- and sex-related cut-offs for AHI.

Attention should be paid also to studying the intermediate phenotypes that have been discussed in the present paper. Already, innovative approaches have been undertaken to better phenotype the craniofacial factors most pertinent to the development of OSAHS (P.A. Cistulli, Royal North Shore Hospital, University of Sydney, Sydney, Australia; personal communication).

\section{CONCLUSION}

Obstructive sleep apnoea/hypopnoea syndrome appears to be a complex polygenic disease. It is possible that a number of intermediate phenotypes interact in different dimensions to produce a single phenotype at a given point in time. The degree of environmental influence is difficult to gauge but is likely to be considerable. Progress in determining the genotype of obstructive sleep apnoea/hypopnoea syndrome is affected by the lack of a consistent definition of phenotype. At the present time we appear to be limited in studying the phenotype at a single point in time and the tools that we have for this are at present very blunt. 


\section{ACKNOWLEDGEMENTS}

The authors thank S. Rafferty (University of Edinburgh, Edinburgh, UK) for all of her help in the preparation of this manuscript.

\section{REFERENCES}

1 Young T, Palta M, Dempsey J, Skatrud J, Weber S, Badr S. The occurrence of sleep-disordered breathing among middle-aged adults. N Engl J Med 1993; 328: 1230-1235.

2 Bearpark H, Elliott L, Grunstein R, et al. Snoring and sleep apnea. A population study in Australian men. Am J Respir Crit Care Med 1995; 151: 1459-1465.

3 Ancoli-Israel S, Kripke DF, Mason W, Kaplan OJ. Sleep apnea and periodic movements in an aging sample. J Gerontol 1985; 40: 419-425.

4 Durán J, Esnaola S, Rubio R, Iztueta A. Obstructive sleep apnea-hypopnea and related clinical features in a population-based sample of subjects aged 30 to $70 \mathrm{yr}$. Am J Respir Crit Care Med 2001; 163: 685-689.

5 Bixler EO, Vgontzas AN, Ten Have T, Tyson K, Kales A. Effects of age on sleep apnea in men: I. Prevalence and severity. Am J Respir Crit Care Med 1998; 157: 144-148.

6 Faccenda JF, MacKay TW, Boon NA, Douglas NJ. Randomized placebo-controlled trial of continuous positive airway pressure on blood pressure in the sleep apnea-hypopoea syndrome. Am J Respir Crit Care Med 2001; 163: 344-348.

7 Pepperell JC, Ramdassingh-Dow S, Crosthwaite N, et al. Ambulatory blood pressure after therapeutic and subtherapeutic nasal continuous positive airway pressure for obstructive sleep apnoea: a randomised parallel trial. Lancet 2002; 359: 204-210.

8 Shahar E, Whitney CW, Redline S, et al. Sleep-disordered breathing and cardiovascular disease: cross-sectional results of the Sleep Heart Health Study. Am J Respir Crit Care Med 2001; 163: 19-25.

9 Marin JM, Carrizo SJ, Vicente E, Augusti AG. Long-term cardiovascular outcomes in men with obstructive sleep apnoea-hypopnoea with or without treatment with continuous positive airway pressure: an observational study. Lancet 2005; 365: 1046-1053.

10 Peppard PE, Young T, Palta M, Skatrud J. Prospective study of the association between sleep-disordered breathing and hypertension. N Engl J Med 2000; 342: 1378-1384.

11 Strohl KP, Redline S. Recognition of obstructive sleep apnea. Am J Respir Crit Care Med 1996; 154: 279-289.

12 Davies RJ, Stradling JR. The relationship between neck circumference, radiographic pharyngeal anatomy, and the obstructive sleep apnoea syndrome. Eur Respir J 1990; 3: 509-514.

13 Pillar G, Shehadeh N. Abdominal fat and sleep apnea: the chicken or the egg? Diabetes Care 2008; 31: Suppl. 2, S303S309.

14 Guilleminault C, Quera-Salva MA, Partinen M, Jamieson A. Women and the obstructive sleep apnea syndrome. Chest 1988; 93: 104-109.

15 Lowe AA, Santamaria JD, Fleetham JA, Price C. Facial morphology and obstructive sleep apnea. Am J Orthod Dentofacial Orthop 1986; 90: 484-491.
16 Mathur R, Douglas NJ. Family studies in patients with the sleep apnea-hypopnea syndrome. Ann Intern Med 1995; 122: 174-178.

17 Scanlan MF, Roebuck T, Little PJ, Redman JR, Naughton MT. Effect of moderate alcohol upon obstructive sleep apnoea. Eur Respir J 2000; 16: 909-913.

18 Wetter DW, Young TB, Bidwell TR, Badr MS, Palta M. Smoking as a risk factor for sleep-disordered breathing. Arch Intern Med 1994; 10; 154: 2219-2224.

19 Lavie P, Fischel N, Zomer J, Eliaschar I. The effects of partial and complete mechanical occlusion of the nasal passages on sleep structure and breathing in sleep. Acta Otolaryngol 1983; 95: 161-166.

20 Redline S, Tishler PV. The genetics of sleep apnea. Sleep Med Rev 2000; 4: 583-602.

21 Ali NJ, Pitson DJ, Stradling JR. Snoring, sleep disturbance, and behaviour in 4-5 year olds. Arch Dis Child 1993; 68: 360-366.

22 Amin RS, Kimball TR, Bean JA, et al. Left ventricular hypertrophy and abnormal ventricular geometry in children and adolescents with obstructive sleep apnea. Am J Respir Crit Care Med 2002; 15;165: 1395-1399.

23 Kheirandish L, Gozal D. Neurocognitive dysfunction in children with sleep disorders. Dev Sci 2006; 9: 388-399.

24 de la Eva RC, Baur LA, Donaghue KC, Waters KA. Metabolic correlates with obstructive sleep apnea in obese subjects. J Pediatr 2002; 140: 654-659.

25 Kalra M, Chakraborty R. Genetic susceptibility to obstructive sleep apnea in the obese child. Sleep Med 2007; 8: 169-175.

26 Gozal D. Congenital central hypoventilation syndrome: an update. Pediatr Pulmonol 1998; 26: 273-282.

27 Pendlebury ST, Pépin JL, Veale D, Lévy P. Natural evolution of moderate sleep apnoea syndrome: significant progression over a mean of 17 months. Thorax 1997; 52: $872-878$.

28 Sforza E, Addati G, Cirignotta F, Lugaresi E. Natural evolution of sleep apnoea syndrome: a five year longitudinal study. Eur Respir J 1994; 7: 1765-1770.

29 Arens R, Marcus CL. Pathophysiology of upper airway obstruction: a developmental perspective. Sleep 2004; 1;27: 997-1019.

30 Malhotra A, Huang Y, Fogel R, et al. Aging influences on pharyngeal anatomy and physiology: the predisposition to pharyngeal collapse. Am J Med 2006; 119: 72.

31 Behan M, Brownfield MS. Age-related changes in serotonin in the hypoglossal nucleus of rat: implications for sleep-disordered breathing. Neurosci Lett 1999; 28;267: 133-136.

32 Riha RL, Brander P, Vennelle M, Douglas NJ. A cephalometric comparison of patients with the sleep apnea/hypopnea syndrome and their siblings. Sleep 2005; 1; 28: 315-320.

33 Pack AI, Silage DA, Millman RP, Knight H, Shore ET, Chung DC. Spectral analysis of ventilation in elderly subjects awake and asleep. J Appl Physiol 1988; 64: 1257-1267.

34 Weaver TE, Chasens ER. Continuous positive airway pressure treatment for sleep apnea in older adults. Sleep Med Rev 2007; 11: 99-111. 
35 Lavie L, Lavie P. Ischemic preconditioning as a possible explanation for the age decline relative mortality in sleep apnea. Med Hypotheses 2006; 66: 1069-1073.

36 Morris AH. Rigorous genotype-phenotype association research depends on scientific rigor at multiple scales of investigation. Crit Care Med 2008; 36: 2956-2958.

37 Ernande B, Dieckmann U. The evolution of phenotypic plasticity in spatially structured environments: implications of intraspecific competition, plasticity costs and environmental characteristics. J Evol Biol 2004; 17: 613-628.

38 American Academy of Sleep Medicine Task Force. Sleep related breathing disorders in adults: recommendations for syndrome definition and measurement techniques in clinical research. Sleep 1999; 22: 667-689.

39 Behrents RG. The biological basis for understanding craniofacial growth during adulthood. Prog Clin Biol Res 1985; 187: 307-319.

40 Lavie P, Rubin AE. Effects of nasal occlusion on respiration in sleep. Evidence of inheritability of sleep apnea proneness. Acta Otolaryngol 1984; 97: 127-130.

41 Thesleff I. The genetic basis of normal and abnormal craniofacial development. Acta Odontol Scand 1998; 56: 321-325.

42 Mina M. Regulation of mandibular growth and morphogenesis. Crit Rev Oral Biol Med 2001; 12: 276-300.

43 Francis-West P, Ladher R, Barlow A, Graveson A. Signalling interactions during facial development. Mech Dev 1998; 75: 3-28.

44 Crummy F, Piper AJ, Naughton MT. Obesity and the lung: 2. Obesity and sleep-disordered breathing. Thorax 2008; 63: 738-746.

45 Kapsimalis F, Varouchakis G, Manousaki A, et al. Association of sleep apnea severity and obesity with insulin resistance, C-reactive protein, and leptin levels in male patients with obstructive sleep apnea. Lung 2008; 186: 209-217.

46 Bouchard C. Genetics of human obesity: recent results from linkage studies. J Nutr 1997; 127: 1887S-1890S.

47 Rankinen T, Zuberi A, Chagnon YC, et al. The human obesity gene map: the 2005 update. Obesity 2006; 14: 529644.

48 Krueger JM, Obal F Jr, Fang J. Humoral regulation of physiological sleep: cytokines and GHRH. J Sleep Res 1999; 8: Suppl. 1, 53-59.

49 Krueger JM, Majde JA. Humoral links between sleep and the immune system: research issues. Ann N Y Acad Sci 2003; 992: 9-20.

50 Williams A, Scharf SM. Obstructive sleep apnea, cardiovascular disease, and inflammation - is NF-кB the key? Sleep Breath 2007; 11: 69-76.

51 Fenik P, Veasey SC. Pharmacological characterization of serotonergic receptor activity in the hypoglossal nucleus. Am J Respir Crit Care Med 2003; 167: 563-569.

52 Kraiczi H, Hedner J, Dahlöf P, Ejnell H, Carlson J. Effect of serotonin uptake inhibition on breathing during sleep and daytime symptoms in obstructive sleep apnea. Sleep 1999; 22: 61-67.

53 Thomas DA, Swaminathan S, Beardsmore CS, et al. Comparison of peripheral chemoreceptor responses in monozygotic and dizygotic twin infants. Am Rev Respir Dis 1993; 148: 1605-1609.
54 Redline S, Tishler PV, Hans MG, Tosteson TD, Strohl KP, Spry K. Racial differences in sleep-disordered breathing in African-Americans and Caucasians. Am J Respir Crit Care Med 1997; 155: 186-192.

55 Rajagopal KR, Abbrecht PH, Tellis CJ. Control of breathing in obstructive sleep apnea. Chest 1984; 85: 174-180.

56 Javaheri S, Colangelo G, Corser B, Zahedpour MR. Familial respiratory chemosensitivity does not predict hypercapnia of patients with sleep apnea-hypopnea syndrome. Am Rev Respir Dis 1992; 145: 837-840.

57 Gold AR, Schwartz AR, Wise RA, Smith PL. Pulmonary function and respiratory chemosensitivity in moderately obese patients with sleep apnea. Chest 1993; 103: 1325-1329.

58 Narkiewicz K, van de Borne PJ, Pesek CA, Dyken ME, Montano N, Somers VK. Selective potentiation of peripheral chemoreflex sensitivity in obstructive sleep apnea. Circulation 1999; 99: 1183-1189.

59 Marcus CL, Gozal D, Arens R, et al. Ventilatory responses during wakefulness in children with obstructive sleep apnea. Am J Respir Crit Care Med 1994; 149: 715-721.

60 Radwan L, Koziorowski A, Maszczyk Z, et al. Respiratory response to inspiratory resistive load changes in patients with obstructive sleep apnoea syndrome. Pneumonol Alergol Pol 2000; 68: 44-56.

61 Ibrahim LH, Patel SR, Modarres M, et al. Measure of ventilatory variability at wake-sleep transition predicts sleep apnea severity. Chest 2008; 134: 73-78.

62 Yaggi HK, Concato J, Kernan WN, Lichtman JH, Brass LM, Mohsenhin V. Obstructive sleep apnea as a risk factor for stroke and death. $N$ Engl J Med 2005; 353: 2034-2041.

63 Ryan S, Nolan GM, Hannigan E, Cunningham S, Taylor C, McNicholas WT. Cardiovascular risk markers in obstructive sleep apnea syndrome and correlation with obesity. Thorax 2007; 62: 509-514.

64 Ryan S, Taylor CT, McNicholas WT. Selective activation of inflammatory pathways by intermittent hypoxia in obstructive sleep apnea syndrome. Circulation 2005; 112: 2660-2667.

65 Riha RL, Brander P, Vennelle M, et al. Tumour necrosis factor-alpha (-308) gene polymorphism in obstructive sleep apnoea-hypopnoea syndrome. Eur Respir J 2005; 26: 673-678.

66 Vgontzas AN, Papanicolaou DA, Bixler EO, Kales A, Tyson K, Chrousos GP. Elevation of plasma cytokines in disorders of excessive daytime sleepiness: role of sleep disturbance and obesity. J Clin Endocrinol Metab 1997; 82: 1313-1316.

67 Vgontzas AN, Papanicolaou DA, Bixler EO, et al. Sleep apnea and daytime sleepiness and fatigue: relation to visceral obesity, insulin resistance, and hypercytokinemia. J Clin Endocrinol Metab 2000; 85: 1151-1158.

68 Wardlaw AJ, Silverman M, Siva R, Pavord ID, Green R. Multi-dimensional phenotyping: towards a new taxonomy for airway disease. Clin Exp Allergy 2005; 35: 1254-1262.

69 Chen D, Wang MW. Development and application of rodent models for type 2 diabetes. Diabetes Obes Metab 2005; 7: 307-317.

70 Richmonds CR, Hudgel DW. Hypoglossal and phrenic motoneuron responses to serotonergic active agents in rats. Respir Physiol 1996; 106: 153-160. 
71 Veasey SC, Panckeri KA, Hoffman EA, Pack AI, Hendricks JC. The effects of serotonin antagonists in an animal model of sleep-disordered breathing. Am J Respir Crit Care Med 1996; 153: 776-786.

72 Lander E, Kruglyak L. Genetic dissection of complex traits: guidelines for interpreting and reporting linkage results. Nat Genet 1995; 11: 241-247.

73 Daly AK, Day CP. Candidate gene case-control association studies: advantages and potential pitfalls. $\mathrm{Br} \mathrm{J} \mathrm{Clin}$ Pharmacol 2001; 52: 489-499.

74 The International HapMap Consortium. A second generation human haplotype map of over 3.1 million SNPs. Nature 2007; 449: 851-861.

75 Tabor HK, Risch NJ, Myers RM. Candidate-gene approaches for studying complex genetic traits: practical considerations. Nat Rev Genet 2002; 3: 391-397.

76 Colhoun HM, McKeigue PM, Davey Smith G. Problems of reporting genetic associations with complex outcomes. Lancet 2003; 361: 865-872.

77 Polotsky VY, O'Donnell CP. Genomics of sleep-disordered breathing. Proc Am Thorac Soc 2007; 4: 121-126.

78 Palmer LJ, Buxbaum SG, Larkin E, et al. A whole-genome scan for obstructive sleep apnoea and obesity. Am J Hum Genet 2003; 72: 340-350.

79 Palmer LJ, Buxbaum SG, Larkin EK, et al. Whole genome scan for obstructive sleep apnoea and obesity in AfricanAmerican families. Am J Respir Crit Care Med 2004; 169: 1314-1321.

80 Zhang J, Zhao B, Gesongluobu, et al. Angiotensinconverting enzyme gene insertion/deletion (I/D) polymorphism in hypertensive patients with different degrees of obstructive sleep apnea. Hypertens Res 2000; 23: 407-411.

81 Lin L, Finn L, Zhang J, Young T, Mignot E. Angiotensinconverting enzyme, sleep-disordered breathing, and hypertension. Am J Respir Crit Care Med 2004; 170: 1349-1353.

82 Patel SR, Larkin EK, Mignot E, Lin L, Redline L. The association of angiotensin converting enzyme (ACE) polymorphisms with sleep apnea and hypertension. Sleep 2007; 30: 531-533.

83 Boström KB, Hedner J, Melander O, et al. Interaction between the angiotensin-converting enzyme gene insertion/deletion polymorphism and obstructive sleep apnoea as a mechanism for hypertension. J Hypertens 2007; 25: 779-783.

84 Li Y, Zhang W, Wang T, Lu H, Wang X, Wang Y. [Study on the polymorphism of angiotensin converting enzyme genes and serum angiotensin II level in patients with obstructive sleep apnea hypopnea syndrome accompanied hypertension]. Lin Chuang Er Bi Yan Hou Ke Za Zhi 2004; 18: 456-459.

85 Bartels NK, Börgel J, Wieczorek S, et al. Risk factors and myocardial infarction in patients with obstructive sleep apnea: impact of beta2-adrenergic receptor polymorphisms. BMC Med 2007; 5: 1.

86 Piérola J, Barceló A, de la Peña M, et al. beta3-Adrenergic receptor Trp64Arg polymorphism and increased body mass index in sleep apnoea. Eur Respir J 2007; 30: 743-747.
87 Zhang LQ, Yao WZ, He QY, Wang YZ, Ren B, Lin TP. Polymorphisms in the beta2 and beta3 adrenergic receptor genes in obstructive sleep apnea/hypopnea syndrome. Zhonghua Nei Ke Za Zhi 2005; 44: 333-336.

88 Lavie L, Lotan R, Hochberg I, Herer P, Lavie P, Levy AP. Haptoglobin polymorphism is a risk factor for cardiovascular disease in patients with obstructive sleep apnea syndrome. Sleep 2003; 1; 26: 592-595.

89 Bayazit YA, Yilmaz M, Ciftci T, et al. Association of the -1438G/A polymorphism of the 5-HT2A receptor gene with obstructive sleep apnea syndrome. ORL J Otorhinolaryngol Relat Spec 2006; 68: 123-128.

90 Sakai K, Takada T, Nakayama H, et al. Serotonin-2A and $2 \mathrm{C}$ receptor gene polymorphisms in Japanese patients with obstructive sleep apnea. Intern Med 2005; 44: 928-933.

91 Ylmaz M, Bayazit YA, Ciftci TU, et al. Association of serotonin transporter gene polymorphism with obstructive sleep apnea syndrome. Laryngoscope 2005; 115: 832-836.

92 Bayazit YA, Yilmaz M, Kokturk O, et al. Association of GABA(B)R1 receptor gene polymorphism with obstructive sleep apnea syndrome. ORL J Otorhinolaryngol Relat Spec 2007; 69: 190-197.

93 Diefenbach K, Kretschmer K, Bauer S, et al. Endothelin-1 gene variant Lys198Asn and plasma endothelin level in obstructive sleep apnea. Cardiology 2008; 112: 62-68.

94 Popko K, Gorska E, Wasik M, et al. Frequency of distribution of leptin receptor gene polymorphism in obstructive sleep apnea patients. J Physiol Pharmacol 2007; 58: Suppl. 5, 551-561.

95 Hanaoka M, Yu X, Urushihata K, Ota M, Fujimoto K, Kubo K. Leptin and leptin receptor gene polymorphisms in obstructive sleep apnea syndrome. Chest 2008; 133: 79-85.

96 Barceló A, Llompart E, Barbé F, Morlá M, Vila M, Agustí AG. Plasminogen activator inhibitor-I (PAI-I) polymorphisms in patients with obstructive sleep apnoea. Respir Med 2002; 96: 193-196.

97 Saarelainen S, Lehtimäki T, Kallonen E, Laasonen K, Poussa T, Nieminem MM. No relation between apolipoprotein E alleles and obstructive sleep apnea. Clin Genet 1998; 53: 147-148.

98 Foley DJ, Masaki K, White L, Redline S. Relationship between apolipoprotein E $\varepsilon 4$ and sleep-disordered breathing at different ages. JAMA 2001; 26; 286: 1447-1448.

99 Kadotani H, Kadotani $\mathrm{T}$, Young $\mathrm{T}$, et al. Association between apolipoprotein E $\varepsilon 4$ and sleep-disordered breathing in adults. JAMA 2001; 13; 285: 2888-2890.

100 Gottlieb DJ, DeStefano AL, Foley DJ, et al. APOE $\varepsilon 4$ is associated with obstructive sleep apnea/hypopnea: the Sleep Heart Health Study. Neurology 2004; 63: 664-668.

101 Wardlaw AJ, Silverman M, Siva R, Pavord ID, Green R. Multi-dimensional phenotyping: towards a new taxonomy for airway disease. Clin Exp Allergy 2005; 35: 1254-1262.

102 Williams RW. Expression genetics and the phenotype revolution. Mamm Genome 2006; 17: 496-502. 